\title{
Por um balé somático: Laban e Béziers no aprenderensinar a técnica clássica
}

\author{
NEILA CRISTINA BALDI
}

Neila Cristina Baldi é mestre e doutora em Artes Cênicas pelo PPGAC/UFBA e docente do Curso de Licenciatura em Dança da Universidade Federal de Santa Maria (UFSM).

AFILIAÇÃO: Universidade Federal de Santa Maria (UFSM) - Santa Maria, RS - Brasil. 


\begin{abstract}
RESUMO
O presente artigo apresenta uma proposta metodológica para o aprenderensinar balé clássico a partir do Sistema Laban/Bartenieff e da Coordenação Motora de Marie-Madeleine Béziers, entendidos como abordagens somáticas. Neste sentido, os procedimentos metodológicos foram desenvolvidos tendo como base princípios destas duas abordagens e da Educação Somática. Desta forma, a proposta metodológica aqui apresentada distancia-se do modo como geralmente as aulas de balé clássico são desenvolvidas, guiadas pelo pensamento do ensino da forma (código da dança clássica), que parte da demonstração dos movimentos, pelos(as) professores(as), e da cópia dos mesmos pelos(as) alunos(as). Na proposta aqui apresentada a chegada ao código da técnica clássica nasce da exploração de movimentos que estão nos princípios desta técnica, utilizando-se de aportes somáticos que ajudam não apenas na aprendizagem da dança clássica, mas também na ressignificação da mesma. Conclui-se que o balé somático pode facilitar o processo de aprendizagem, bem como torná-lo mais significativo, e favorecer a autonomia do sujeito frente à construção do seu conhecimento em dança no/pelo corpo.
\end{abstract}

PALAVRAS-CHAVE

Balé clássico, Educação Somática, Sistema Laban, Coordenação Motora.

\title{
- ABSTRACT
}

This paper shows one methodological proposal for learningteaching classical ballet form Laban/Bartenieff System and Motor Coordination de Marie-Madeleine Béziers, understood as somatic approach. In this sense, the methodological procedures were developed based on the principles of these two approaches and Somatic Education. In this way, the methodological proposal presented here distances itself from the way in which classical ballet classes are usually developed, guided by the thought of the teaching of form (classical dance code), which starts from the demonstration of movements, by teachers, and the copy of the same by the students. $n$ the proposal presented here the arrival of the classical technique code is born from the exploration of movements that are in the principles of this technique, using somatic contributions that help not only in the learning of classical dance, but also in the re-signification of the same. It is concluded that the somatic ballet can facilitate learning, as well as making it meaningful and promoting the autonomy of the subjects facing their knowledge construction in dance in/by body.

\section{KEYWORDS}

Classical Ballet, Somatic Education, Laban System, Motor Coordination. 


\section{Introdução}

O balé clássico se caracterizou, nos últimos séculos, por um ensino diretivo, em que o(a) professor(a) mostrava ao(à) aluno(a) o movimento e este(a) copiava-o. O presente texto busca apresentar outra abordagem para a aprendizagem desta técnica de dança. Partindo do pressuposto de que aprender e ensinar são indissociáveis, este artigo discute uma proposta metodológica de aprenderensinar balé clássico a partir do Sistema Laban/Bartenieff e da Coordenação Motora, de MarieMadeleine Béziers, consideradas aqui abordagens somáticas. Este balé somático, então, se utiliza de procedimentos que nascem dos princípios gerais da Educação Somática ou destas duas abordagens, tendo como pano de fundo o entendimento de que o conhecimento se constrói - ou seja, filiando-se epistemologicamente ao Construtivismo Pós-Piagetiano.

Para apresentar este balé somático, inicialmente discorro sobre a Educação Somática e suas características. Posteriormente, mostro como o Sistema Laban e a Coordenação Motora podem ser considerados abordagens somáticas. A partir destas duas apresentações - das características e princípios da Educação Somática, de modo geral, e do Sistema Laban e da Coordenação Motora, de modo mais específico - elenco os procedimentos que norteiam o trabalho com este balé somático. Por fim, apresento conclusões a respeito desta proposta metodológica de aprenderensinar balé clássico somaticamente.

\section{Características da Educação Somática}

A Educação Somática nasceu no início do século passado, com o desenvolvimento de técnicas e métodos corporais que tinham em comum a integração corpomente. Nos anos 1970, o filósofo Thomas Hanna olhou para diversas práticas corporais e identificou características em comum - autorregulação, autocorreção, automelhoria e autoconsciência - nomeando o campo como Educação Somática. Nos 20 anos seguintes, a Educação Somática passa a ser utilizada em várias áreas, entre elas a dança, culminando com o desenvolvimento, a partir do final do século passado de práticas mescladas e do surgimento das chamadas abordagens somáticas - práticas corporais que se utilizam de princípios somáticos ou de princípios de técnicas e métodos somáticos.

Além das características apresentadas por Hanna (1977), a partir de Bolsanello (2005), Domenici (2010), Fortin (1999, 2011), Hanna (1986/88), Lima (2010) e Strazzacappa (2009a, 2009b e 2012b), elenco os seguintes princípios da Educação Somática, que são utilizadas nesta proposta de balé somático: privilégio à informação que vem do corpo, descoberta pessoal, autorregulação, reconhecimento de padrões, corpo saudável, mudança de ritmo e integração.

Apesar de não separar corpo e mente, na Educação Somática muitas vezes há referências ao corpo - do ponto de vista de estrutura musculoesquelética ou como unidade corpomente. O privilégio à informação que vem do corpo é aqui entendido como o privilégio às informações da experiência vivida, ao processo, uma vez que: o interesse é "[...] pelo corpo por meio da experiência do 'eu'. Ali é valorizada uma subjetividade que se educa e se refina de uma sessão a outra por estratégias 
pedagógicas precisas." (FORTIN, 2011, p. 30) São consideradas sensações, percepções, emoções etc., tanto a partir de si quanto da observação de outra pessoa.

Outro princípio comum na Educação Somática, é o da descoberta pessoal, em que o(a) aluno(a) descobre como se move e como pode se mover, tornando-se "[...] investigador do seu próprio movimento e conquistando uma posição de autonomia." (DOMENICI, 2010, p. 75)

A partir de si, o(a) aluno(a) chega à autorregulação: "Será esta apropriação que provocará as mudanças no universo em que as ações estão se dando e, por consequência, como uma onda, manifestar-se-á em todos os seus confins." (LIMA, 2010 , p. 62) Ao se investigar, o sujeito se percebe, se autorregula, se autocorrige. E só faz tudo isso porque reconhece seus padrões de movimento.

Outro princípio da Educação Somática é a busca do corpo saudável no sentido de prevenção/manutenção da saúde, sobretudo ao que diz respeito ao alinhamento musculoesquelético, sem perder de vista que uma questão física pode estar relacionada ao psíquico. De acordo com Débora Bolsanello (2009, p. 17) busca-se: "[...] utilizar o movimento do corpo na recuperação e na manutenção da saúde; mover-se de forma consciente por uma melhor qualidade de vida."

Outra característica comum nas práticas somáticas é da mudança de ritmo (que geralmente é diminuído para aumentar a autopercepção). Esta mudança de ritmo tem um sentido de: "[...] ser capaz de sentir para agir, tal é um leitmotiv da Educação Somática. Agir no intuito de aumentar as possibilidades de escolha, logo, aumentar sua liberdade." (FORTIN, 1999, p. 44)

Por fim, não se pode esquecer que na Educação Somática, a integração não é só corpomente. Uma mudança em um aspecto corresponde a uma alteração no todo. É por isso que Rebecca Weber (2009), por exemplo, fala da integração da percepção com a ação.

\section{Balé com princípios somáticos}

Nesta proposta metodológica, o princípio do privilégio à informação que vem do corpo pode aparecer de diversas formas, todas ligadas à escuta corporal. Por exemplo: perceber onde está o peso do corpo ao caminhar. Ou tocar o colega, manipulando-o, indicando direcionamentos ósseos. Um modo de favorecer esta escuta é fechar os olhos. Como é sentir o caminho do movimento durante um tendu? Como é fazê-lo mudando a sua iniciação: pela cabeça do fêmur, pelo calcanhar, pela ponta do pé? O que isso provoca no movimento?

A descoberta pessoal talvez seja o princípio somático mais visível nesta proposta metodológica, uma vez que a chegada ao código do balé clássico se dá pela exploração dos verbos essenciais desta dança - dobrar, estender, elevar, girar, lançar, deslizar e saltar. Os(as) alunos(as) experimentam esses verbos em diferentes partes do corpo, compreendendo-os cinestesicamente, para depois investigarem combinações e chegarem a um movimento específico. A exploração, e consequente descoberta pessoal, pode surgir também da pesquisa a partir da Categoria Expressividade. Por exemplo, chegar ao chassé (que é um deslizar) a partir da investigação de que é uma ação direta, leve e sustentada. Outro procedimento que atende a este princípio somático é o de solicitar a construção de sequências: ou seja, os(as) 
estudantes precisam descobrir como fazer variações, como fazer ligações entre movimentos etc.

O procedimento de fechar os olhos favorece também que se chegue a outro princípio somático: o da autorregulação. Nas aulas tradicionais de balé clássico as pessoas se acostumam a se regular pelo espelho. Evito usar o espelho e peço aos(às) alunos(as) que percebam como estão executando o movimento e por indicações verbais ou às vezes por toque tento ajudá-los(as) quando é necessária uma autorregulação.

Durante as aulas, os(as) estudantes são incentivados(as) a reconhecer padrões, das mais diferentes formas. Por exemplo: reconhecer que costuma colocar o peso em tal parte e desalinhar-se. Ou de que inicia sempre o movimento por tal parte. Ou ainda que tem a tendência de usar determinada dinâmica de movimento.

O reconhecimento dos padrões - assim como a descoberta pessoal - permite a emergência do "corpo saudável" que, no dançar balé se manifesta no acionamento das musculaturas mais adequadas, em não fazer esforços desnecessários, em reaprender a pisar o pé no chão etc.

Outro princípio somático, o da mudança de ritmo - neste caso, mais lento é incentivado nas minhas aulas, para auxiliar na memorização de sequências, na percepção do caminho do movimento etc.

Por sua vez, o princípio da integração pode se dar no entendimento de que a percepção das partes ajuda na (re)criação do todo (FERNANDES, 2010), numa perspectiva de Integração Corporal Total (HACKNEY 1998 apud FERNANDES, 2010). Nas minhas aulas, trabalhamos as partes do corpo por vez, dando ênfase a um segmento, de modo que essa consciência da parte venha a ajudar na percepção do todo e modificá-lo. A integração se dá também nos conteúdos abordados: dança-expressividade-estrutura corporal. Por exemplo: se estou trabalhando com o alinhamento dos pés, dou ênfase a movimentos de balé que utilizem esta parte do corpo.

\section{Pensamentos somáticos em Laban e Béziers}

Enxergo tanto no Sistema Laban quanto na Coordenação Motora, de Béziers, um pensamento somático. Ambas as teorias foram desenvolvidas no século passado. O Sistema Laban, na primeira metade, e a Coordenação Motora, na segunda.

Nos anos 1960, Marie-Madeleine Béziers desenvolveu estudos sobre a motricidade humana junto com Suzanne Piret, que culminaram com o que ela chama de Coordenação Motora. Estes estudos tinham um pensamento diferenciado na fisioterapia: até então trabalhava-se as consequências e não as causas dos problemas dos(as) pacientes, nem havia relação com o psiquismo. Enquanto na psicologia não havia relação com as questões motoras. Na abordagem da Coordenação Motora, todo gesto é carregado de psiquismo, o que significa que aspectos psicológicos interferem nos motores e vice-versa. Na Coordenação Motora, podese "[...] compreender o movimento como um todo organizado, capaz de situar-se paralelamente ao psiquismo, com ele e perante ele. Então um poderá ser estudado em função do outro." (BÉZIERS; PIRET, 1992, p. 13) Ou seja, é evidente o pensa- 
mento da Educação Somática de unidade corpomente.

De acordo com Marie-Madeleine Béziers, nossa coordenação motora se dá a partir do alinhamento ósseo, provocado por um movimento espiralado. Nas minhas aulas, a Coordenação Motora aparece como estudos anatômicos em movimento. $\mathrm{O}(\mathrm{a})$ estudante reconhece sua estrutura ósseo-muscular e, a partir de pesquisas de movimento, chega a um dos seus princípios: o da torção/tensão. Com base neste princípio é que reconhecem seus desenhos corporais, vivenciando como se dá esta coordenação motora.

Para Paola Bianchi e Sandra Meyer Nunes (2015, p. 159), os oitos presentes na nossa coordenação - vindos do movimento espiralado dos ossos - fazem "[...] com que o movimento do corpo nunca se paralise, propiciando uma qualidade corporal dinâmica em ondas que se propagam sem interrupção." É por isso que elas afirmam que: "O equilíbrio na Coordenação Motora se baseia na relação entre forças opositoras. [...] O equilíbrio não é fixo, mas um jogo cinético ininterrupto." (BIANCHI e NUNES, 2015, p. 162)

Neste sentido, os estudos anatômicos em movimento nas minhas aulas se dão a partir do osso: "O osso é um apoio concreto para sentirmos o nosso corpo como integrado." (BALDI, 2014a, p. 101) Este trabalho se dá no alinhamento da estrutura musculoesquelética e no pensar no movimento a partir do osso: como é fazer o mesmo tendu a partir do dedão, da rotação coxofemoral, etc.

Muitos princípios da Educação Somática podem ser verificados na Coordenação Motora. Por exemplo, segundo Paola Bianchi e Sandra Meyer Nunes (2015, p. 164): "A gênese da Coordenação Motora está no restabelecimento ou na manutenção, da saúde do corpo. [...]". Outro princípio visível é o da autorregulação. Béziers e Piret (1992) diziam que, em um processo de reeducação era preciso, com a participação da pessoa, fazer com esta modificasse a imagem de seu corpo e, assim chegasse a uma nova maneira de se mover. De acordo com Juliana Storto (2005, p. 56): "Na prática, Béziers insistia na educação do olhar." Ou seja, a pessoa (re)aprendia a olhar-se, mesmo que muitas vezes, inicialmente, fosse o toque do(a) fisioterapeuta que o auxiliasse.

Não há nos escritos de Béziers nenhuma referência à desaceleração do movimento, à mudança do ritmo - um dos princípios da Educação Somática. No entanto:

\begin{abstract}
A Coordenação Motora propõe que se experiencie o mesmo gesto em diferentes planos e em diferentes relações com o espaço, para ser possível perceber a mudança na forma desse gesto. Essa experimentação afeta o modo de perceber e captar o espaço numa via de mão dupla: ao experimentar novas formas de movimento no espaço-motor, descobrem-se novas formas e orientações no ambiente (Béziers; Piret, 1992), assim como a percepção e a interação com o ambiente fazem emergir diferentes maneiras de movimentar-se. [...]. (BIANCHI; NUNES, 2015, p.160) (grifo das autoras)
\end{abstract}

Outro princípio é o da integração: cada unidade de coordenação está associada a outra e assim sucessivamente.

Assim como a Coordenação Motora, também vejo o Sistema Laban como 
uma abordagem somática, bem como enxergo relações entre as duas teorias. Para Laban, do mesmo modo que Béziers, o equilíbrio do ser humano se dá em movimento. É por isso que, para ele, era importante que cada pessoa aprendesse a usar de forma consciente os fatores do movimento, tanto como prevenção quanto como terapia. Ele também enxergava a unidade corpomente, pois dizia que: "Há duas causas fundamentais que obstruem um fácil domínio do movimento: inibições de ordem física e de ordem mental." (LABAN, 1978, p. 194)

Também presente em Laban é o princípio do privilégio à informação que vem do corpo. Segundo Isabel Marques (2005, p. 147), Laban "[...] sugere como aprendizado uma maior consciência das sensações e dos esforços necessários para a organização dos movimentos individuais."

Nas minhas aulas, o Sistema Laban aparece, sobretudo, a partir da Categoria Expressividade - fatores do movimento. Mas não só. No livro Dança Educativa Moderna (LABAN, 1990, p. 16), ele diz que: "Em vez de estudar cada movimento particular, pode-se compreender e praticar o princípio do movimento." Isso tem relação direta com o uso dos verbos na minha proposta metodológica. Parto dos princípios dos movimentos codificados, ou seja, dos chamados verbos essenciais do balé - e sua exploração - para chegarmos ao alfabeto desta dança. O que significa que, para aprender um plié, o(a) aluno primeiro explora o verbo dobrar - plier em francês - entende-o cinestesicamente, para então, por meio de explorações, chegar ao dobrar os joelhos do plié.

Uso o pensamento de Laban também explorando os fatores do movimento, de duas formas: na pesquisa de movimento - o deslizar do chassé é uma ação básica de esforço - e na ressignificação do gesto: como é fazer um grand battement com peso forte? Como isso muda a intenção do movimento? Cadence Whittier (2006) afirma que aprender balé clássico a partir do Sistema Laban torna o processo mais criativo, pois os(as) estudantes são desafiados a explorar as possibilidades do movimento. Outra vantagem do uso do Sistema Laban nas aulas de balé é apontada por Paula Salosaari (2001): a de que quando mudamos a intenção no gesto e, ao mesmo tempo, prestamos atenção aos conteúdos do vocabulário, as formas de realização se tornam múltiplas.

\section{Procedimentos somáticos para aprenderensinsar balé clássico}

A partir do entendimento de que o Sistema Laban e a Coordenação Motora podem ser considerados abordagens somáticas, proponho alguns procedimentos baseados nestas duas teorias do movimento e em princípios somáticos.

Como a demonstração do movimento não é o princípio pelo qual chego ao alfabeto do balé clássico, um dos procedimentos básicos do meu trabalho em sala de aula diz respeito ao dos verbos do balé clássico. São sete os verbos considerados essenciais: dobrar, estender, elevar, girar, saltar, lançar e deslizar (PAVLOVA, 2000) Segundo Akiko Yuzurihara (2012), mais de 70\% dos movimentos codificados do balé clássico derivam de verbos. Neste sentido, primeiro exploramos os verbos, para depois chegarmos aos movimentos codificados do balé clássico.

Com os movimentos construídos, vivenciamos-nos de diversas formas. Uma das maneiras é realizá-los de olhos fechados. Esta prática é muito comum em téc- 
nicas e métodos somáticos. Posso pedir que os(as) alunos fechem os olhos aos fazerem pesquisa de movimento ou ao executarem sequências prontas: Como é realizar o mesmo movimento feito de olhos abertos agora de olhos fechados? Ao fechar os olhos, o(a) estudante é convidado a não buscar feedback externo e, neste sentido, voltar-se para si. De acordo com Klauss Vianna (2005, p. 74): "A obrigatoriedade da observação me faz mais vivo, me faz ouvir mais, me faz olhar com atenção, faz que eu reflita e tenha informações diferentes sobre o meu corpo." Este procedimento tem relação direta com outro, auxiliando-o: a perceber o caminho do movimento. A ideia é não pensar na forma de um grand battement, por exemplo, mas pensar anatomicamente como este movimento se dá, qual o caminho que o corpo percorre.

Se por um lado os(as) estudantes são convidados a pensar o movimento a partir de si, outro procedimento comum é a observação do(a) colega. De acordo com David Mead (2012), o feedback do colega é mais efetivo, uma vez que o(a) estudante tende a ficar mais confortável com seu colega. Neste sentido, muitas vezes o feedback do(a) outro está relacionado à execução do movimento ou ao alinhamento ósseo.

Outro procedimento é o de pensar no osso. Posso, por exemplo, solicitar que pensem o movimento a partir de um osso: Como é executar um tendu pelo calcanhar ou pelos ísquios? Ou que criem uma movimentação/célula de movimento a partir de um osso. Ou ainda que alterem a intenção de uma célula de movimento a partir de uma nova iniciação por outro osso. No Sistema Laban/Bartenieff, pensar a partir do osso tem relação com a Iniciação e Sequenciamento do Movimento, em que: "Uma mesma ação pode ser realizada de maneiras totalmente distintas, dependendo de qual parte inicia e qual(is) parte(s) dá(dão) continuidade ao movimento." (FERNANDES, 2006, p. 67)

O entendimento a partir do osso também pode se dar a partir de um princípio da Coordenação Motora: o das torções. Proponho que os(as) alunos(as) façam torções de unidades de coordenação para encontrar o alinhamento ósseo.

Do mesmo modo, a mesma ação pode começar pelo lado não usual - se sou destra, como é começar a fazer o movimento pelo lado esquerdo? Trata-se de se descondicionar, pois muitas vezes nos acostumamos a fazer sempre pelo mesmo lado, do mesmo jeito...

A partir do Sistema Laban, outro procedimento presente nas minhas aulas é a variação dinâmica dos movimentos: como é fazer um movimento tipicamente lento e deixando-o acelerar, o que isso provoca na intenção do gesto? Posso também chegar ao movimento codificado a partir da exploração das dinâmicas (ações básicas de Laban.).

Também costumo solicitar nas minhas aulas que os(as) estudantes criem células coreográficas ou sequências para a barra. Para mim, estes momentos servem de sistematização de conhecimento. De acordo com Cadence Whittier (2006), desafiar os(as) estudantes a criar seus próprios movimentos é uma forma de avaliar a compreensão deles(as) a respeito da técnica clássica.

A criação coreográfica, nas minhas aulas, pode partir desde os movimentos codificados do balé clássico, da Categoria Expressividade (peso, fluência, tempo e espaço), dos verbos essenciais da técnica clássica ou dos ossos. Do mesmo modo, 
as células criadas podem sofrer diversas modificações, a partir dos procedimentos somáticos elencados anteriormente.

Além desses procedimentos, utilizo também alguns recursos metodológicos, como por exemplo: a bolinha de tênis, para sentir os arcos dos pés, bexigas e sacos pesados - para diferenciar peso leve e forte - barbante colado ao ísquio, dando o caminho do alinhamento ísquio-calcâneo.

Segundo Cadence Whittier (2006) , quando a compreensão da técnica é articulada com o toque, a fala, a escrita, o desenho etc., ou seja, quando o(a) professor(a) não apenas se utiliza da demonstração do movimento, as experiências tornam-se mais profundas.

\section{Aprendendoensinando somaticamente}

O balé somático aqui proposto permite a construção de conceitos de movimentos codificados desta técnica e, desta forma, fazer com que esta dança possa ser pensada como uma língua viva, que pode ter, então, neologismos. Do mesmo modo, que esta construção - e não a forma pronta - ajuda na compreensão do movimento e, portanto, facilita a aprendizagem do mesmo. Esta proposição metodológica ajuda os(as) alunos(as) a se perceberem, possibilitando a autoformação e a autonomia.

Do mesmo modo, é possível verificar que a anatomia em movimento - a partir da Coordenação Motora - pode ajudar a não apenas compreender o alinhamento esquelético-muscular durante a dança, como também a compreender os movimentos do balé clássico, dando outras significações e expressões a estes, e ajudar a pessoa perceber-se. E que outra forma de aprender e ensinar balé clássico altera o jeito de se pensar balé clássico.

\section{Referências}

BÉZIERS, Marie-Madeleine.PIRET, Suzzane. A coordenação motora: aspecto mecânico da organização psicomotora do homem. 3ํㅡ. Ed. São Paulo: Summus Editorial. 1992.

BIANCHI, Paloma. NUNES, Sandra Meyer. A coordenação motora como dispositivo para criação: uma abordagem somática na dança contemporânea. In: Revista Brasileira de Estudos da Presença, Porto Alegre, v. 5, n.1, p. 148-168. Jan/abr. 2015.

BOLSANELO, Debora. In: BOLSANELO, Debora. Nosso corpo não é somente nosso. In: BOLSANELLO, Débora Pereira (org). Em pleno corpo - educação somática, movimento e saúde. Curitiba: Juruá Psicologia, 2009. p.16-30.

BOLSANELO, Debora. Educação somática: o corpo enquanto experiência. Motriz, Rio Claro, v.11, n.2, p.99-106, mai./ago. 2005.

DOMENICl, Eloisa. O encontro entre dança e educação somática como uma interface de questionamento epistemológico sobre as teorias do corpo. Pro-Posições, Campinas, v. 21, n. 2 (62), p. 69-85, maio/ago. 
FERNANDES, Ciane. Criatividade, conexão e integração: Uma introdução à obra de Irmgard Bartenieff. BOLSANELLO, Débora Pereira (org). Em Pleno Corpo: Educação Somática, Movimento e Saúde. $2^{\mathfrak{a}}$ ed. Curitiba: Juruá, 2010, p. 34-48.

FERNANDES, Ciane. O corpo em movimento: o sistema Laban/Bartenieff na formação e na pesquisa em artes cênicas. 2ª Ed. São Paulo: Annablume, 2006.

FORTIN, Sylvie. Nem do lado direito, nem do lado avesso: o artista e suas modalidades de experiência de si e do mundo. In: WOSNIAK, Cristiane. MARINHO, Nirvana. O avesso do avesso do corpo - educação somática como práxis. Seminários de dança 4. Joinville: Nova Letra, 2011. p. 27-42

FORTIN, Sylvie. Educação somática: novo ingrediente na formação prática em dança. Cadernos do GIPE-CIT, Salvador, n. 2, p. 40-55, fev. 1999.

HANNA, Thomas. What is somatics? Somatics: Magazine-Journal of the Bodily Arts and Sciences, local, V. 4-6, p. 1986/88. Disponível em: < http://somatics.org/library/htl-wis4.html> Acesso em 06 out. 2013

HANNA, Thomas. The somatic healers and the somatic educator. In: SOMATICS: Magazine-Journal of the Bodily Arts and Sciences, Volume I, No. 3, Autumn 1977. Disponível em: <http://somatics.org/library/htl-somatichealed.html >.Acesso em 02 fev..2014.

LABAN, Rudolf. Dança educativa moderna. São Paulo; Ícone Editora, 1990.

LABAN, Rudolf. Domínio do movimento. São Paulo: Summus editorial, 1978.

LIMA, Jose. Educação somática: limites e abrangências. Pro-posições. Campinas, v. 21, n.2, p 51-68, mai/ago 2010

MARQUES, Isabel. Dançando na escola. 2aㅡ ed. São Paulo: Cortez, 2005.

MEAD, David. Developing the expressive artist: Constructive creativity in the technique class. In: STINSON, Susan; NIELSEN, Charlotte Svendler; LIU, Shu-Ying Liu (Ed.). Dance, young people and change: proceedings of the daCi and WDA Global Dance Summit. Taiwan: Taipei National University of the Arts, 2012. Disponível em: < http://ausdance.org.au/uploads/content/publications/2012-global-summit/education-dance-teachers-artists-rp/developing-the-expressive-artist-1.pdf >. Acesso em: 9 fev. 2016.

PAVLOVA, Anna. Novo dicionário de ballet. Rio de Janeiro: Nórdica, 2000.

SALOSAARI, Paula. Multiple embodiment in classical ballet. Educating the Dancer as an Agent of Change in the Cultural Evolution of Ballet. 2001. 149 fls. Tese (Doutorado em Artes Cênicas ). Theatre Academy, Yliopistopaino,. 2001. 
STORTO, Juliana Nogueira. Coordenação motora. In: RIBEIRO, Ana Rita, SOUZA, Fátima Andrade, MAGALHÃES, Romero (org). Catálogo de Abordagens terapêuticas. São Paulo: Casa do Psicólogo, 2005. p. $55-58$

STRAZZACAPPA, Márcia. Educação somática e artes cênicas: princípios e aplicações. Campinas: Papirus, 2012.

STRAZZACAPPA, Márcia. As técnicas de educação somática In: BOLSANELLO, Débora Pereira (org). Em pleno corpo - educação somática, movimento e saúde. Curitiba: Juruá Psicologia, 2009b. p. 309-318.

STRAZZACAPPA, Márcia. Educação somática: princípios e possíveis desdobramentos. Repertório - Teatro e Dança, Salvador, ano 12, número 13, p. 48-54, 2009.2 (a)

VIANNA, Klauss. A dança. São Paulo: Siciliano, 2005.

WEBER, Rebecca. Integrating semi-structured somatic practices and contemporary dance technique training. Journal of Dance and Somatic Practices, local, V.1, N.2, p. 237-254, 2009. Disponível em:

$<$ http://www.researchgate.net/publication/274325214_Integrating_semi-structured_somatic_practi-

ces_and_contemporary_dance_technique_training >. Acesso em: 08 jun. 2015.

WHITTIER, Cadence. Laban Movement Analysis Approach to Classical Ballet Pedagogy. Journal of Dance Education. Silver Spring: National Dance Education Organization, V. 6, N. 4, 2006. p.124-132. Disponível em: < http://www.tandfonline.com/doi/abs/10.1080/15290824.2006.10387325?journalCode=ujod20> Acesso em: 8 fev. 2016

YUZURIHARA, Akiko. The construction of classical dance vocabulary in the light of the principle of variation: a comparison with the compositional techniques of contemporary dance. Comparative Theater Review, v. 12, n. 1 (English Issue), p. 133-145, March 2013. Disponível em:

<https://www.jstage.jst.go.jp/article/ctr/12/1/12_133/_article>. Acesso em: 1 nov. 2016.

Recebido em 14/09/2017 - Aprovado em 12/11/2017.

\section{Como citar:}

BALDI, Neila. Por um balé somático: Laban e Béziers no aprenderensinar a técnica clássica. ouvirOUver; Uberlândia, v.14.n.2, p510-520, jul./dez. 2018. Disponível em: http://www.seer.ufu.br/index.php/ouvirouver; DOI:http://doi.org/10.14393/OUV23-v14n2a2018-18 